\title{
Parallel wind turbine powertrains and their design for high availability
}

\author{
Alasdair McDonald and Godwin Jimmy
}

\begin{abstract}
Conventional wind turbine powertrains tend to use single-input-single-output topologies (i.e. one gearbox coupled to a generator with a power converter). Here powertrains with single-input-multiple-output subsystems are analyzed with Markov state space models in order to quantify any improvements in availability. A baseline powertrain's availability and that of different parallel powertrains are evaluated using wind turbine powertrain failure and repair rate data. The results show that an increase in the number of parallel systems, $N$, does not automatically lead to a higher availability for a wind turbine powertrain; however when failure and repair rates scale with module power ratings then there is an improvement. The designer can further improve availability by over-rating each parallel module. The net benefit of parallel powertrains depends both on the turbine and the type of powertrain technology.
\end{abstract}

Index Terms - availability, Markov state space model, parallel subsystems, powertrain, wind turbine.

\section{INTRODUCTION}

$\mathrm{M}$ AXIMISING the availability of offshore wind turbines is critical to increasing their annual energy production and hence reduce the levelized cost of energy. Other industries - such as oil and gas, aerospace and electrical power generation, transmission and distribution infrastructure - make use of redundancy and fault tolerance when it is important to have high availability [1-4]. Offshore wind turbine operating conditions are challenging with access for maintenance being limited by weather to a greater degree than for onshore turbines. This makes operational costs more expensive since maintenance access involves dispatching crews by helicopter, crew transfer vessel or heavy lift vessels to execute maintenance. A combination of these costs and any resulting loss of energy production will tend to increase the cost of energy of offshore wind farms.

\section{A. Wind turbine powertrains}

The design of wind turbine powertrain has been a subject of interest to industry and researchers with significant amount of engineering and scientific literature devoted to the investigation of potential configurations. Many of these configurations and state-of-the-art powertrain designs are structured with one torque/speed conversion device (e.g.

A. McDonald and G. Jimmy are with the Institute of Energy and Environment, Department of Electronic and Electrical Engineering, University of Strathclyde, Glasgow G1 1XW, UK. (e-mail: alasdair.mcdonald@strath.ac.uk; godwin.jimmy@strath.ac.uk). gearbox) coupled to one generator which in turn is connected to a power converter. Some turbines are gearless (direct-drive) while others are "fixed speed" and do not require a power converter. The gearbox, generator and power converter are usually single devices and the power is not normally split between parallel gearboxes, generators or power converters.

Extensive research has been made on the various powertrain configurations. The geared drive system was compared with the direct-drive systems in [5] while the various generator technologies for wind turbines have been examined [6-7]. Diverse metrics such as reliability, initial capital cost, efficiency, cost of energy and annual energy production have been used as arguments in the optimization and selection of technologies. Failure rate data has been used to compare the reliability of wind turbine powertrain components [8-9]. In spite of these efforts to draw conclusions on the optimum powertrain design, there is still a divergence in opinion.

\section{B. Parallel powertrains}

A parallel powertrain topology has at least one of its subsystems (e.g. gearbox, generator, power converter) made up of parallel components so that if a failure occurs in one such parallel subsystem, some power can still be converted by the other subsystems that still function. This parallelism can be introduced in the gearbox, generator, power converter or a combination thereof. Some schematic examples are given in Fig. 1.

Relatively few analyses have been reported on the subject of parallel powertrain components as a means of providing partial redundancy and availability improvements in wind turbine systems [10-12]. As a consequence of the inherent challenges of weather dependent access to offshore wind turbines, the subject of availability has become more important. This paper pays particular attention to the relative turbine availability when parallel powertrain units are used. It is proposed that during certain powertrain fault scenarios the turbine continues to operate at a reduced power level. Reference [13] suggests that one of the means of increasing wind turbine availability is to have redundancy as it reduces the influence of failure on the turbine's reliability.

In [10-11], parallel powertrains with six generators were compared with other configurations in terms of cost. This powertrain, similar to that adopted by Clipper has a gearbox with a single low speed input shaft and multiple high speed output shafts [14]. Should one of the generators fail while the others carry on generating, the application of forces on the bull 
gear will be imbalanced, potentially damaging the gearbox bearings. The magnitude of imbalance is reduced somewhat by using a larger number of generators and can be further reduced by switching out other generators to compensate. A system of parallel generators can help the design of certain power converters to reach different ranges of voltage [12]. A power split concept for high-speed parallel generators with possibilities of repair time reduction has also been examined [15]. Some designers have opted for a conventional gearbox arrangement deciding to introduce the parallel nature into the generator itself, for example by using modular or multi-phase windings connected to parallel converters as used in Gamesa turbines [16]. As with gearboxes, the torque imbalance in a fault scenario needs to be considered for radial-flux generators.

\section{This paper}

The novelty of this work lies in the modelling of the availability of a wind turbine parallel powertrain using a Markov state space approach and the development of a method for finding the expected net benefit of using such a system. The paper finds that equivalent availability can be increased when using a parallel powertrain. It is noteworthy that this improvement is not inherent to the parallel nature of the powertrain but rather it comes about because the parallel powertrain employs smaller units of powertrain (which tend to have lower failure rates and higher repair rates) and because these units can be over-rated thereby reducing the energy loss consequence of a powertrain failure.

This paper examines the use of modular generators and power converter units in offshore wind turbines and how they can be designed to maximize the wind turbine's energy production. Section II describes the development of Markov state space models and their use to find a figure of effective availability. This is done for a simplified case and then a more realistic case, so that effective availability can be found for any $N$ parallel powertrains, where each parallel powertrain is rated at $P / N$ (where $P$ is the wind turbine's power rating).

A further development comes from the fact that as $N$ increases, the size of the equipment in each parallel powertrain becomes smaller and so the failure rate and repair rate may change. These effects are introduced into the model. As a final extension, the paper examines the power rating of the parallel powertrain units, developing the model allowing the power rating of the generator and converter to vary between $P / N$ and $P$. Section III presents the results for these models. Section IV discusses these results and interprets them in the context of an offshore wind turbine of $3 \mathrm{MW}$ power rating. Finally the paper draws conclusions in light of the case study and highlights some of the limitations of the methodology.

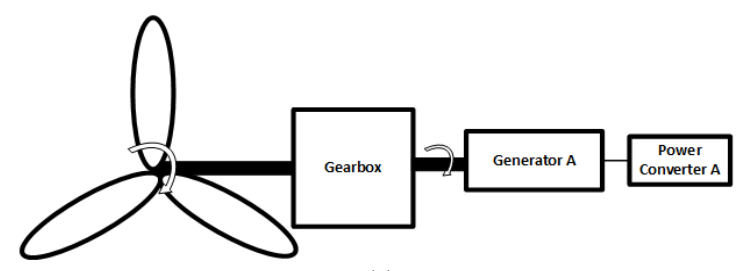

(a)

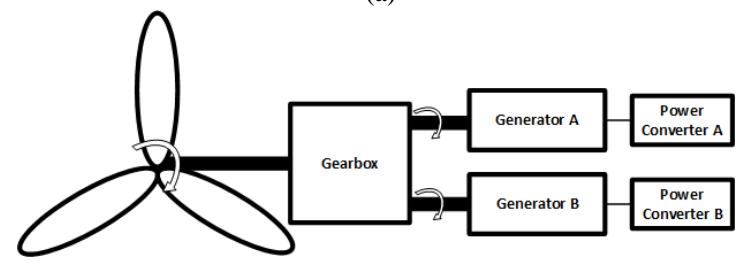

(b)

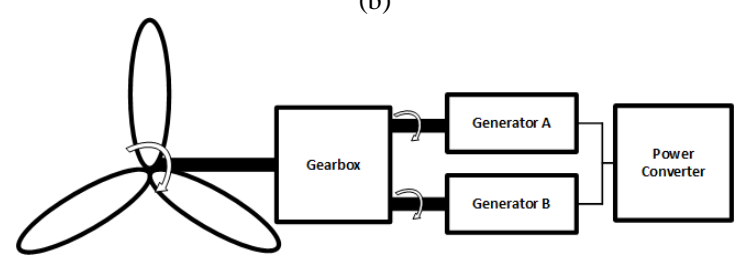

(c)

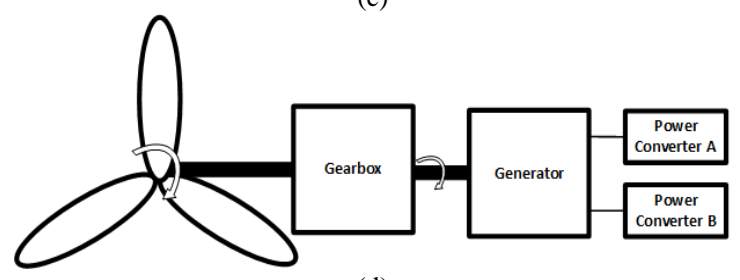

(d)

Fig. 1. Wind turbine powertrains: (a) Single-input-single-output system, $N=$ 1 (b) Powertrain system with both generator and power converter in parallel, $N=2$ (c) Powertrain system with only generator in parallel, $N=2$ (d) Powertrain system with only power converter in parallel, $N=2$

\section{Methodology}

Fig. 1(a) shows a wind turbine powertrain with a single gearbox, single generator and single power converter; Fig. 1(b) shows the same turbine powertrain with a single gearbox with $N=2$ (two parallel generators and power converters). Each generator is connected to the power converter; hence a combined failure and repair rate is used for the two components. The availability of the system was analyzed using failure and repair data from the wind turbine industry. The parallel powertrain was also considered for separate cases where the powertrain consist of parallel generators only (Fig. 1(c)) and then only power converters in parallel (Fig. 1(d)).

\section{A. Markov state space modeling}

Markov state space modeling (MSSM) involves the transition of components between states, with failure rates and repair rates being used to calculate the probability of being in these different states. Markov state space modeling has been used for many years now in the evaluation of reliability [1]. In [17] it was used to model the reliability of power converters more effectively than other reliability modeling tools. Although many papers using MSSM have been published, it has not yet been used to evaluate the equivalent availability of parallel powertrains of wind turbines. 
In a simple case, shown in Fig. 2, a 3MW turbine system can either be in an operating state ("Up") or a failed state ("Down"). When operating, the turbine can produce up to 3MW (depending on the wind speed); when in the failed state the turbine produces $0 \mathrm{MW}$.

In this paper, systems with $N$ parallel components are considered; the power output is reduced depending on the number of parallel components in the system. The failure and operating transition of the system is modeled using the failure rates, $\lambda$, and repair rates, $\mu$, of the system. The limiting state probability of the system is derived using the transitional probability matrix equation of the MSSM.

\section{1) Simple Markov model for $N=1$}

The conventional baseline wind turbine, has a gearbox connected to the generator and the converter which could be described as a series model of the system as shown in Fig. 1(a). As indicated in the state space model, this series model has no intermediate state space levels meaning that it can only produce power at $3 \mathrm{MW}$ depending on available wind speeds or no power (0MW). The symbol $\lambda$ represents the failure rate and implies the system going from being "Up" (State 1) to "Down" (State 2) while $\mu$ symbolizes the repair rate meaning transition from "Down" to "Up".

In matrix form, the limiting state probabilities of being in State 1, $p_{1}$, and State 2, $p_{2}$, are represented as,

$$
\left[\begin{array}{ll}
p_{1} & p_{2}
\end{array}\right]\left[\begin{array}{ll}
p_{11} & p_{12} \\
p_{21} & p_{22}
\end{array}\right]=\left[\begin{array}{ll}
p_{1} & p_{2}
\end{array}\right]
$$

where $\left[\begin{array}{ll}p_{11} & p_{12} \\ p_{21} & p_{22}\end{array}\right]=\left[\begin{array}{cc}1-\lambda & \lambda \\ \mu & 1-\mu\end{array}\right]=P \quad$ is $\quad$ the transitional probability matrix and $p_{11}$ describes the probability when in State 1 of remaining in State $1, p_{12}$ describes the probability of transitioning from State 1 to State 2, $p_{22}$ describes the probability when in State 2 of remaining in State 2 and $p_{21}$ describes the probability of transitioning from State 2 to State 1 . This can be done more generally for any $N$ [11]. Knowing that the probabilities sum to unity, i.e $p_{1}+p_{2}+\ldots+p_{N+1}=1$, then (1) can be interpreted as

$$
A X=b,
$$

where $b=\left[\begin{array}{l}0 \\ 0 \\ \vdots \\ 1\end{array}\right], X=\left[\begin{array}{l}p_{1} \\ p_{2} \\ \vdots \\ p_{N+1}\end{array}\right]$ and $A$ is the coefficient matrix

derived from the set of simultaneous equations. Then $X$ can be solved by using $X=A^{-1} b$ i.e. multiplying the column vector $b$ by the inverse of coefficient matrix $A$ to get the probabilities at State 1 and 2 as,

$$
\begin{aligned}
& p_{1}=\frac{\mu}{(\mu+\lambda)}, \\
& p_{2}=\frac{\lambda}{(\mu+\lambda)} .
\end{aligned}
$$

When in State 1 - and the wind speed is between rated wind speed and cut-out wind speed - the powertrain power is the rated wind turbine power, $P_{1}=P$ (in this case $3 \mathrm{MW}$ ).
When in State 2, the powertrain power is 0 . The simple availability of the powertrain system is given by $p_{1}$. In order to compare this with the availability of systems with $N>1$, a concept of "equivalent availability" is introduced. This is the sum of the products of power and probability for all $N+1$ states divided by the rated power,

$$
A_{\mathrm{eq}}=\frac{\sum_{x=1}^{x=N+1} P_{x} p_{x}}{P} .
$$

Substituting the probabilities and power at each state into (5) gives the equivalent availability for $N=1$,

$$
A_{\text {eq, } N=1}=\frac{P_{1} p_{1}+P_{2} p_{2}}{P}=\frac{\mu}{(\mu+\lambda)} .
$$

Equation (6) then gives the availability of the baseline powertrain, i.e. with a simple series connection. The next subsection will develop expressions for equivalent availability for $N=2$ and then more generally $N$.

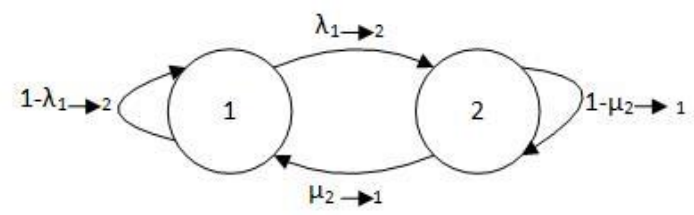

Fig. 2. State space model of a single component, $N=1$ system

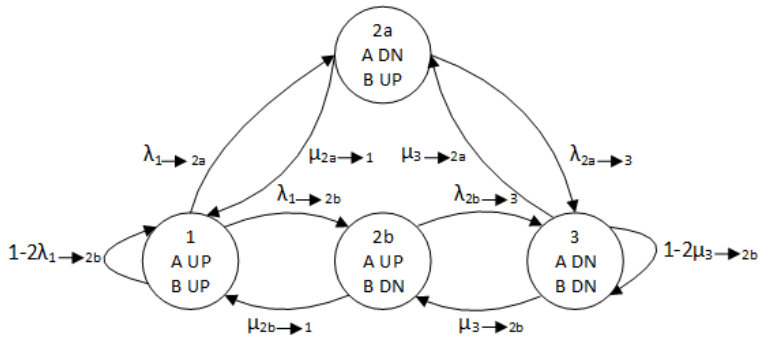

(a)

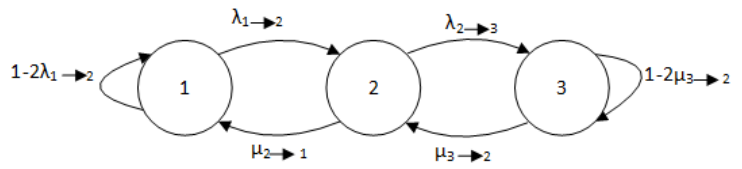

(b)

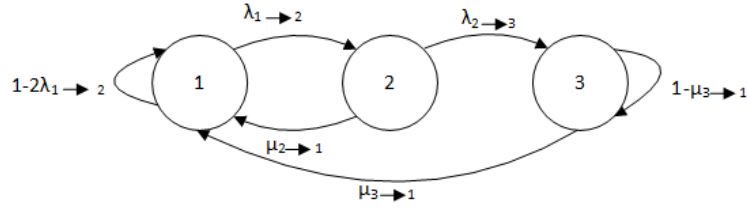

(c)

Fig. 3. State space model of two parallel components, $N=2$ system: (a) Simplified model with four states (b) Simplified model with reduced states (c) Simplified model with alternative repair path.

\section{2) Simple Markov model for $N=2$}

Fig. 3(a) gives the Markov state space diagram for $N=2$, shown in Fig. 1(b). State 1 is when both subsystem A (i.e. Generator A and Power Converter A) and subsystem B are "Up"; State 3 is when both subsystems are "Down". State 2a and $2 b$ are equivalent as they both represent the case when one of the parallel subsystems is "Down" and lead to power output reducing to $50 \%$. Assuming that the failure rates are equal $\left(\lambda_{\mathrm{A}}\right.$ $\left.=\lambda_{\mathrm{B}}=\lambda\right)$ and the repair rates are equal $\left(\mu_{\mathrm{A}}=\mu_{\mathrm{B}}=\mu\right)$ then the 
probability of being in states $2 \mathrm{a}$ and $2 \mathrm{~b}$ are equal, and they can be combined to give State 2 in a simplified diagram in Fig. 3(b).

In matrix form, the limiting state probabilities are represented as,

$$
\left[\begin{array}{lll}
p_{1} & p_{2} & p_{3}
\end{array}\right]\left[\begin{array}{lll}
p_{11} & p_{12} & p_{13} \\
p_{21} & p_{22} & p_{23} \\
p_{31} & p_{32} & p_{33}
\end{array}\right]=\left[\begin{array}{lll}
p_{1} & p_{2} & p_{3}
\end{array}\right]
$$

where $\left[\begin{array}{lll}p_{11} & p_{12} & p_{13} \\ p_{21} & p_{22} & p_{23} \\ p_{31} & p_{32} & p_{33}\end{array}\right]=\left[\begin{array}{ccc}1-2 \lambda & 2 \lambda & 0 \\ \mu & 1-\mu-\lambda & \lambda \\ 0 & 2 \mu & 1-2 \mu\end{array}\right]$. For two parallel components, the probabilities of States 1,2 and 3 can be found by using straightforward substitution or matrix techniques and are,

$$
\begin{aligned}
& p_{1}=\frac{\mu^{2}}{(\mu+\lambda)^{2}}, \\
& p_{2}=\frac{2 \mu \lambda}{(\mu+\lambda)^{2}}, \\
& p_{3}=\frac{\lambda^{2}}{(\mu+\lambda)^{2}} .
\end{aligned}
$$

The denominator for each is $(\mu+\lambda)^{2}$ and the numerator for each probability can be found using the binomial expansions, for $N=2$,

$$
(\mu+\lambda)^{2}=\left(\begin{array}{l}
2 \\
2
\end{array}\right) \mu^{2}+\left(\begin{array}{l}
2 \\
1
\end{array}\right) \mu \lambda^{2-1}+\left(\begin{array}{l}
2 \\
0
\end{array}\right) \lambda^{2},
$$

where $\left(\begin{array}{l}N \\ r\end{array}\right)=\frac{N !}{r !(N-r) !}$.

For $N=2$, when the wind speed is between rated wind speed and cut-out wind speed, the power output for State 1 is $P_{1}=P$, for State 2 it is $P_{2}=P / 2$ and for State 3 it is $P_{3}=0$. Using (5), the equivalent availability $A_{\text {eq }}$ of the two parallel powertrain model can then be evaluated as,

$$
A_{\mathrm{eq}, N=2}=\frac{P p_{1}+\frac{P}{2} p_{2}}{P}=\frac{\mu(\mu+\lambda)}{(\mu+\lambda)^{2}}=\frac{\mu}{(\mu+\lambda)} .
$$

It is worthy of remark that the equivalent availability is the same for $N=2$ as it is for $N=1$ (given by (6)).

\section{3) Simple Markov model for $N$}

The simple model can be extended for any $N$. The more general form of the binomial expansion for $N$ leads to,

$$
\begin{aligned}
& (\mu+\lambda)^{N}=\left(\begin{array}{l}
N \\
N
\end{array}\right) \mu^{N} \lambda^{0}+\left(\begin{array}{c}
N \\
N-1
\end{array}\right) \mu^{N-1} \lambda^{1}+\ldots+\left(\begin{array}{l}
N \\
1
\end{array}\right) \mu^{1} \lambda^{N-1}+ \\
& \left(\begin{array}{l}
N \\
0
\end{array}\right) \mu^{0} \lambda^{N} .
\end{aligned}
$$

From this the probabilities of states of the first two and the last two states are,

$$
p_{1}=\frac{\left(\begin{array}{l}
N \\
N
\end{array}\right) \mu^{N}}{(\mu+\lambda)^{N}}
$$

$$
\begin{gathered}
p_{2}=\frac{\left(\begin{array}{c}
N \\
N-1
\end{array}\right) \mu^{N-1} \lambda}{(\mu+\lambda)^{N}} \\
p_{N-1}=\frac{\left(\begin{array}{l}
N \\
1
\end{array}\right) \mu^{1} \lambda^{N-1}}{(\mu+\lambda)^{N}} \\
p_{N}=\frac{\left(\begin{array}{l}
N \\
0
\end{array}\right) \lambda^{N}}{(\mu+\lambda)^{N}} .
\end{gathered}
$$

The reader should note that States $3,4, \ldots, N-2$ have been omitted for brevity. The power output of the states are $P_{1}=P$, $P_{2}=P(N-1) / N, \ldots, P_{N-1}=P / N, P_{\mathrm{N}}=0$. Combining this with (14-17) and applying (5) leads to a general result for any $N$,

$$
\begin{aligned}
& A_{\mathrm{eq}, N}=\frac{P p_{1}+P \frac{N-1}{N} p_{2}+\cdots+P \frac{1}{N} p_{N-1}}{P}=\frac{\mu(\mu+\lambda)^{N-1}}{(\mu+\lambda)^{N}}= \\
& \frac{\mu}{(\mu+\lambda)},
\end{aligned}
$$

i.e. the equivalent availability in this simplified model is independent of the number of parallel subsystems, $N$.

\section{B. Developed case with more realistic repair transition paths}

The simple model in subsection IA is reasonable in that it assumes that failure transitions are independent, however it is limited by the repair transition paths. The model present in Fig. 3(b) is not very realistic, as it is likely that if the wind turbine powertrain was in State 3, repair would be carried out on two of the subsystems (i.e. returning the system to State 1), rather than just one subsystem (i.e. returning the system to State 2). Indeed the repair rate for $\mu_{2 \rightarrow 1}$ and $\mu_{3 \rightarrow 1}$ are likely to be approximately the same once logistic and weather window delays are taken into account. Fig. 3(c) shows the developed case, where the repair transition paths have been updated. It is assumed that $\mu_{N \rightarrow 1}=\mu_{3 \rightarrow 1}=\mu_{2 \rightarrow 1}=\mu$. The transitional probability matrix for the developed state space model for $N=$ 2 parallel subsystems then becomes

$$
\left[\begin{array}{lll}
p_{11} & p_{12} & p_{13} \\
p_{21} & p_{22} & p_{23} \\
p_{31} & p_{32} & p_{33}
\end{array}\right]=\left[\begin{array}{ccc}
1-2 \lambda & 2 \lambda & 0 \\
\mu & 1-\mu-\lambda & \lambda \\
\mu & 0 & 1-\mu
\end{array}\right] \text {. }
$$

The probabilities of being in States 1 to 3 are,

$$
\begin{gathered}
p_{1}=\frac{\mu(\mu+\lambda)}{(\mu+2 \lambda)(\mu+\lambda)}=\frac{\mu}{(\mu+2 \lambda)} \\
p_{2}=\frac{2 \mu \lambda}{(\mu+2 \lambda)(\mu+\lambda)} \\
p_{3}=\frac{2 \lambda^{2}}{(\mu+2 \lambda)(\mu+\lambda)} .
\end{gathered}
$$

Generally the denominator for these probabilities is given by $(\mu+N \lambda)(\mu+(N-1) \lambda) \ldots(\mu+\lambda)$ for $N$ parallel subsystems. Applying (5) with probabilities given by (20-22) leads to,

$$
A_{\mathrm{eq}, N=2}=\frac{P p_{1}+\frac{P}{2} p_{2}}{P}=\frac{\mu(\mu+\lambda)+\mu \lambda}{(\mu+2 \lambda)(\mu+\lambda)}=\frac{\mu}{(\mu+\lambda)} .
$$


The reader should note that this is the same equivalent availability as given by the simple model. Higher values of $N$ were evaluated using symbolic computation software (Maple). In every case the same equivalent availability was observed.

\section{Case with failure and repair rates changing with $N$}

In the previous sections, a constant failure rate was assumed for the parallel powertrain subsystems, regardless of the power rating and physical size. However data from industry shows that failure rate and repair rates of electrical machines vary with their size [18-20]. Similar assessments have also been published for the wind turbine industry showing powertrain components' failure and repair rates varying with their size [21-23]. Spinato et al. [22] discuss how generator winding failures rates vary with machine torque rating with regards to failure rates in high speed and direct drive generators. This is because a higher torque rating implies that a machine has more coils, connections and a larger insulation surface area that can fail. A similar rationale can be extended to generator failures for increased power rating. There is also evidence that failure rates in power converters vary with power rating, especially when the number of identical converter modules is increased [24].

Table I gives some examples of the varying failure rate $\lambda$. The generators include a mixture of electrical machine types, and the failure rate given is a composite of the different generators from each source. The lower power ratings tend to be dominated by constant speed stall regulated turbines, whereas the higher ratings are variable speed pitch regulated machines. The final population has the largest turbines and they are all offshore. This population has the highest failure rate. There is a modest correlation between generator failure rate and power rating. The power converter failure rate with power rating has a very strong correlation.

Table I Estimated average failure rate (failures per wind turbine per year) of wind turbine powertrain components based on power rating [21-24]

\begin{tabular}{lccccc}
\hline Wind turbine rating (MW) & $\leq 0.3$ & 0.6 & $\geq 1$ & $1.5-2.5$ & $2.8-3.5$ \\
& & {$[22-23]$} & & {$[24]$} & {$[21]$} \\
\hline Generator $\lambda$ (/year) & 0.10 & 0.55 & 0.25 & $0.08-$ & 1.00 \\
& & & & 0.12 & \\
Squirrel Cage Induction & Yes & Yes & Yes & - & - \\
Direct Drive Synchronous & - & Yes & Yes & - & - \\
Doubly Fed Induction & - & - & Yes & Yes & Yes \\
PM Synchronous & - & - & - & Yes & - \\
Power converter $\lambda$ (/year) & - & 0.01 & - & $0.11-$ & 0.18 \\
& & & & 0.59 & \\
\hline
\end{tabular}

Table II Estimated downtime of wind turbine powertrain components based on powertrain rating [21-23, 25]

\begin{tabular}{lccccc}
\hline Wind turbine rating & $\leq 0.3$ & 0.6 & $\geq 1$ & \multicolumn{2}{c}{$2.8-3.5$} \\
$(\mathrm{MW})$ & & {$[22-23]$} & Repair & $\begin{array}{c}\text { Down- } \\
\text { time [21] }\end{array}$ & time [25] \\
\hline Generator (hours) & 40 & 52 & 70 & 20 & 147 \\
Power converter (hours) & - & 15 & 23 & 12 & - \\
\hline
\end{tabular}

In general this change in failure rate from the assumed baseline failure rate can be taken into account using a modifying coefficient, $a$. For example the failure rate of a subsystem in a $N=2$ system is given by $\lambda_{2}=a_{2} \lambda$ where $\lambda$ is the baseline (i.e. $N=1$ ) failure rate and $a_{2}$ is the modifying coefficient for when $N=2$. When $a<1$ it implies that the subsystem failure rate is less than the baseline and when $a>1$ it implies that the failure rate is greater than the baseline. By substituting $\lambda_{N}=a_{N} \lambda$ into (18) it is possible to see the effect that this has on the equivalent availability,

$$
A_{\text {eq, } N}=\frac{\mu}{\left(\mu+a_{N} \lambda\right)} \text {. }
$$

By taking in all of the wind turbine generator and power converter failure rate data from Table $\mathrm{I}$, it is possible to characterize a generic powertrain, i.e. one which is independent of a particular turbine powertrain type. By plotting the failure rates against power the relationship of subsystem failure rate as a function of power rating is found to be

$$
\lambda_{\text {subsy stem }}=m_{\lambda} P_{\text {subsy stem }}+c_{\lambda},
$$

where $m_{\lambda}=0.357$ powertrain subsystem failures per year per MW when $c_{\lambda}=0$ powertrain subsystem failures per year (i.e. if the powertrain subsystem is rated at $0 \mathrm{MW}$ there are no failures). If the baseline failure rate is $\lambda=m_{\lambda} P$ and with $P_{\text {subsystem }}=P / N$ it can be seen that $a_{\mathrm{N}}=1 / N$. As $N$ increases then the equivalent availability increases.

A similar process can be used to modify the repair rate using a modifying coefficient, $b$. Table II shows how the downtime (and hence repair rate $\mu$ ) can vary. When $b<1$ it implies that the subsystem takes longer to repair than the baseline and when $b>1$ it implies that the subsystem repair process is quicker than the baseline. By substituting $\mu_{N}=b_{N} \mu$ into (24) it is possible to see the effect that this has on the equivalent availability,

$$
A_{\text {eq, } N}=\frac{b_{N} \mu}{\left(b_{N} \mu+a_{N} \lambda\right)} .
$$

The repair time is likely to increase with larger units of the parallel powertrain as component sizes and numbers increase. Wind turbine generator and power converter downtimes based on Table II were analyzed to give subsystem mean time to repair $(M T T R)$ as a function of power rating for a generic powertrain,

$$
M T T R_{\text {subsy stem }}=m_{M T T R} P_{\text {subsy stem }}+c_{M T T R},
$$

where $m_{M T T R}=0.0073$ years per powertrain subsystem repair per MW. For offshore sites, there is likely to be some delay which is independent of the power rating, e.g. delays taken up by travel time, waiting for weather to allow access and so on. This can be seen in the final columns of Table II, which show the difference in time spent in the turbine and the total downtime for each failure. However in order to simplify the model it was assumed that $c_{M T T R}=0$ years, i.e. if the subsystem is rated at $0 \mathrm{MW}$ then the subsystem takes no time to repair. To find the repair rate from (27), one notes that $\mu=1$ /MTTR and so, 


$$
\mu_{\text {subsy stem }}=\frac{1}{m_{M T T R} P_{\text {subsy stem }}+c_{\text {MTTR }}} .
$$

If the baseline repair rate is $\mu=1 /\left(m_{M T T R} P_{\text {subsytsem }}\right)$ and with $P_{\text {subsystem }}=P / N$ it can be seen that $b_{N}=N$. As $N$ increases then the equivalent availability increases because of the improved repair rate.

\section{Case with varying parallel powertrain subsystem power rating}

Thus far it has been assumed that the power rating of the subsystems in the parallel system is given by $P_{\text {subsystem }}=P / N$. At the design stage there is freedom to choose the power rating of individual generators and power converters, so that $P_{\text {subsystem }}$ $=\alpha P$ where $(1 / N) \leq \alpha \leq 1$. Although the installed powertrain and available capacity, $N \alpha P$, may be greater than the wind turbine rating, the system output power is limited by the wind turbine rating, $P$. This applies for all states, e.g. for $N$ parallel subsystems, the installed powertrain and available capacity in State 1 is $N \alpha P$ but the output is limited to $P_{1}=P$; when one subsystem fails the installed powertrain and available capacity is $(N-1) \alpha P$ but the output is limited so that $P_{2} \leq P$. This can be expressed by using another variable, $\beta$, as shown

$$
\begin{aligned}
& A_{\mathrm{eq}, N}=\beta_{1}\left(\begin{array}{l}
N \\
N
\end{array}\right) \frac{\left(b_{N} \mu\right)^{N}}{\left(b_{N} \mu+a_{N} \lambda\right)^{N}}+\beta_{2}\left(\begin{array}{c}
N \\
N-1
\end{array}\right) \frac{\left(b_{N} \mu\right)^{N-1}\left(a_{N} \lambda\right)}{\left(b_{N} \mu+a_{N} \lambda\right)^{N}} \\
& +\cdots+\beta_{N-1}\left(\begin{array}{l}
N \\
1
\end{array}\right) \frac{\left(b_{N} \mu\right)\left(a_{N} \lambda\right)^{N-1}}{\left(b_{N} \mu+a_{N} \lambda\right)^{N}}+\beta_{N}\left(\begin{array}{l}
N \\
0
\end{array}\right) \frac{\left(a_{N} \lambda\right)^{N}}{\left(b_{N} \mu+a_{N} \lambda\right)^{N}}
\end{aligned}
$$

where $\beta_{1}=\left\{\begin{array}{l}1, \text { if } N \alpha>1 \\ N \alpha, \text { if } N \alpha \leq 1\end{array}, \beta_{2}=\left\{\begin{array}{l}1, \text { if }(N-1) \alpha>1 \\ (N-1) \alpha, \text { if }(N-1) \alpha \leq 1\end{array}, \ldots\right.\right.$, $\beta_{N-1}=\left\{\begin{array}{l}1, \text { if } \alpha>1 \\ 2 \alpha, \text { if } \alpha \leq 1\end{array}\right.$ and $\beta_{N}=\left\{\begin{array}{l}1, \text { if } \alpha>1 \\ 2 \alpha, \text { if } \alpha \leq 1\end{array}\right.$.

For a given $N$, this leads to availability being a function of $\alpha$. Plotting availability against $\alpha$ shows that there are different gradients in the intervals between $\alpha=1 / N, 1 /(N-1), \ldots, 1$. This change in gradient can be modeled using Macaulay brackets,

$$
\begin{aligned}
& \text { i.e }\langle\alpha-x\rangle=\left\{\begin{array}{l}
0, \alpha<x \\
\alpha-x, \alpha \geq x
\end{array}\right. \text { in (30) } \\
& A_{\mathrm{eq}}=\frac{\mu}{(\mu+\lambda)}+\left\langle\alpha-\frac{1}{N}\right\rangle\left(\gamma_{1}+\gamma_{2}+\cdots+\gamma_{N-1}\right)-\left\langle\alpha-\frac{1}{N-1}\right\rangle \gamma_{1}- \\
&\left\langle\alpha-\frac{1}{N-2}\right\rangle \gamma_{2}-\cdots-\left\langle\alpha-\frac{1}{2}\right\rangle \gamma_{N-1}
\end{aligned}
$$

where $\gamma_{1}=(N-1)\left(\begin{array}{c}N \\ N-1\end{array}\right) \frac{\mu^{N-1} \lambda}{(\mu+\lambda)^{N}}$,

$\gamma_{2}=(N-2)\left(\begin{array}{c}N \\ N-2\end{array}\right) \frac{\mu^{N-2} \lambda^{2}}{(\mu+\lambda)^{N}}, \quad \gamma_{N-1}=N \frac{\mu \lambda^{N-1}}{(\mu+\lambda)^{N}}$.

\section{E. Net benefit and case studies}

To investigate the 'net benefit' expected from parallel powertrains as a result of their improved powertrain availability, a site was used with four different types of powertrain configurations. A simple (non-discounted) net benefit can be calculated,
Net benefit $=\Delta$ revenue due toparallel powertrain

- $\Delta$ costs due to parallel powertrain

A 3MW turbine with a life of 25 years, a baseline capacity factor 0.35 (with mean wind speed of $8.4 \mathrm{~m} / \mathrm{s}$, and a 'rest of turbine' availability, $A_{\mathrm{RoT}}=0.97$ ) was assumed. Some of the details for this turbine at an IEC Class IIA site [26] can be seen in the 'Site 1' entry in Table III. The overall turbine availability, $A_{\mathrm{T}}$ is given by $A_{\mathrm{RoT}} A_{\text {eq }}(N, \alpha)$ where $A_{\text {eq }}(N, \alpha)$ comes from Section IID and is based on a variable failure and repair rate. It is assumed that the turbine owner receives $£ 120$ per MWh of electrical power generated. The powertrain costs were taken from $[25,27]$. In reality, cost per unit power is not constant, nor is the mass and volume per unit power. Larger power units tend to be more effective in terms of per unit cost, mass and volume, however at larger power ratings the variation with power or number of units is relatively modest. In this paper, to simplify the analysis the baseline powertrain costs were scaled by $N \alpha$ where appropriate. For every $N, \alpha$ was varied until the maximum net benefit was found.

A sensitivity analysis was carried out for different powertrain types using the data in Table IV; this gives the turbine availability and coefficients for different powertrain types based on [24].

A further sensitivity analysis was performed on the same turbine using different failure and repair rate data from a number of sources [21, 23-24] to see the impact of these inputs on the net benefit.

As well as the case that the generator and power converter are configured in parallel units, it is possible to introduce the parallelism into the generator only or the power converter only. The methods described above were adapted and used to analyze and compare the equivalent availability and net benefit of three cases: (a) generator and power converter both in parallel (Fig. 1b), (b) parallel generator only (Fig. 1c) and (c) parallel converter only (Fig. 1d). Table V show details of the data used in the analysis, essentially the generic powertrain failure and repair rate as used before but with the failure and repair rate separated. In the case when only the generator is in a parallel configuration, the rest of the turbine availability from (a) is reduced to include the downtime for the power converter with $N=1$; the analysis is conducted with $m_{\lambda}, m_{M T T R}$ and costs for the generator. Similarly in the case when only the power converter is in a parallel configuration, the rest of the turbine availability from (a) is reduced to include the downtime for the generator with $N=1$; the analysis is conducted with $m_{\lambda}, m_{M T T R}$ and costs for the power converter.

A final sensitivity analysis was carried out by repeating the analysis for two other sites which have higher mean wind speeds (both IEC Class IA). Although the sites are different, the $3 \mathrm{MW}$ turbine power curve was considered to be the same for all 3 sites. The increase in energy capture was modelled using a Rayleigh probability distribution. Higher mean wind speeds also lead to an increase in turbine and powertrain failure rates. The failure rate to mean wind speed relationship in [21] was used to change the failure rates and this can be seen in the availability in Table III. The three sites are all 
$10 \mathrm{~km}$ from shore and it was assumed that the altered wind speed distribution did not affect the turbine or powertrain repair rate.

Table III: Wind turbine and site details for sensitivity analysis

\begin{tabular}{lccc}
\hline & Site 1 & Site 2 & Site 3 \\
\hline IEC Wind Class & IIA & IA & IA \\
Mean wind speed (m/s) & 8.4 & 9.5 & 10 \\
Rest of Turbine failure rate & 8.21 & 9.91. & 10.7 \\
(failures/turbine/year) & & & \\
Availability Rest of Turbine (-) & 0.97 & 0.964 & 0.961 \\
Generator and power converter failure & 0.36 & 0.43 & 0.47 \\
rate per MW (failures/MW/year) & & & \\
$N=1$ generator and power converter & 1.07 & 1.29 & 1.40 \\
failure rate (failures/turbine/year) & & & \\
Availability $N=1$ generator and power & 0.977 & 0.973 & 0.971 \\
converter (-) & & & \\
\hline
\end{tabular}

Table IV: Data for sensitivity analysis for different 3MW powertrain types

\begin{tabular}{lcc}
\hline & $m_{\lambda}$ & $m_{M T T R}$ \\
\hline DFIG 3 stage gearbox & 0.39 & 0.0052 \\
PMG 3 stage gearbox & 0.47 & 0.0035 \\
PMG 2 stage gearbox & 0.49 & 0.0035 \\
PMG direct drive & 0.51 & 0.0035 \\
\hline
\end{tabular}

Table V: Input data for different parallel powertrain configurations: (a) Generator and power converter in parallel (b) Parallel generator only (c) Parallel power converter only

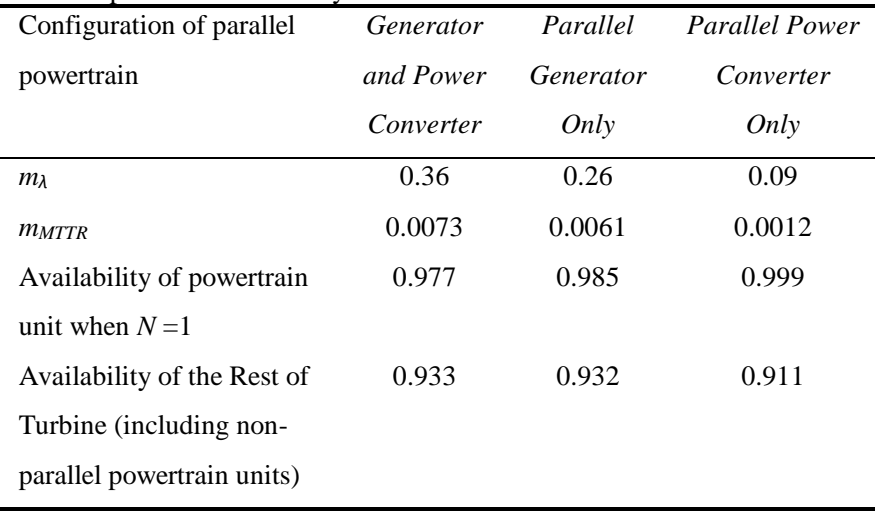

\section{RESUlts AND SENSITIVITY ANALYSES}

The results of the methods outlined in Section II are shown in Figs. 4-8. This is first done with generic powertrain data to find the powertrain equivalent availability and then this is used to estimate the net benefit for this population of turbines and others. Results for different generator and power converter types and parallel powertrain configurations are presented. The sensitivity of the net benefit to factors such as assumed failure rate data, assumed repair rate data and the nature of the wind turbine site is then shown.

\section{A. Results for a generic powertrain}

Fig. 4 gives the result of the availability for a $3 \mathrm{MW}$ generic wind turbine powertrain with a failure rate of 1.07 failures per turbine per year and a repair rate of 46 repairs per turbine per year $\left(m_{\lambda}=0.357\right.$ powertrain subsystem failures per year per MW and $m_{M T T R}=0.0073$ years per powertrain subsystem repair per MW). It shows the equivalent availability for $N=2$, $3,4,5$ and 6 against $\alpha$. The result shows that a higher value of $N$ gives a wider range of possible values of $\alpha$. The largest increase in $A_{\text {eq }}$ is given when $\alpha$ changes from $1 / N$ to $1 /(N-1)$; the highest availability is achieved when $\alpha=1$. The lowest availability is observed when $\alpha=1 / N$ for each $N$. If $\alpha=1 / N$, $A_{\text {eq }}$ is independent of $N$.

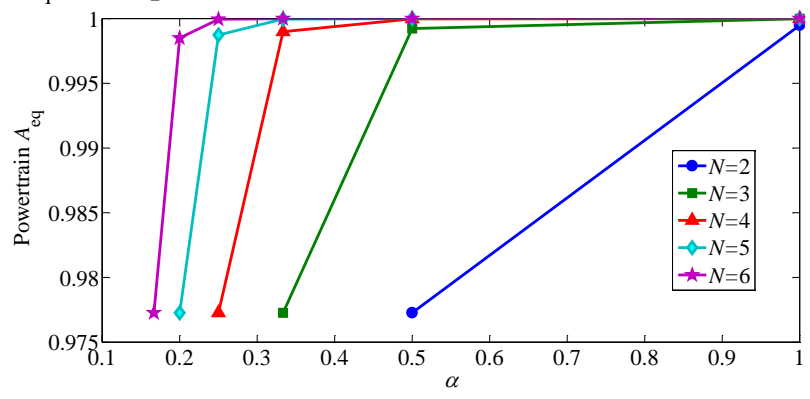

Fig. 4. Effect of $\alpha$ and $N$ on the equivalent availability of a 3MW parallel wind turbine powertrain based on generic powertrain failure $\left(m_{\lambda}=0.357\right)$ and repair data $\left(m_{M T T R}=0.0073\right)$

\section{B. Results for different powertrain topologies}

Each point on Fig. 4 has both an equivalent availability and a powertrain cost. The net benefit of each point was calculated using equation (31); the result for the maximum value for each $N$ is shown in Fig. 5. There are five curves, one for each powertrain configuration in Table IV and also a curve for a generic powertrain with the data described in Section IIC $\left(m_{\lambda}=\right.$ 0.357, $m_{M T T R}=0.0073$ ).

Fig. 5 shows that using larger $N$ generally gives a higher net benefit, with the effect leveling out at different $N$ for different powertrain types. For the specific powertrain types, the powertrain with the highest net benefit is the DFIG - this has the lowest availability in the baseline case $(N=1)$ [25]. In order to positively benefit from parallelism, $N$ has to be higher for the powertrains with already high baseline availability (e.g. the direct drive PMG). For these powertrain topologies (which tend to have higher capital cost), $N>2$ before there is a significant benefit.

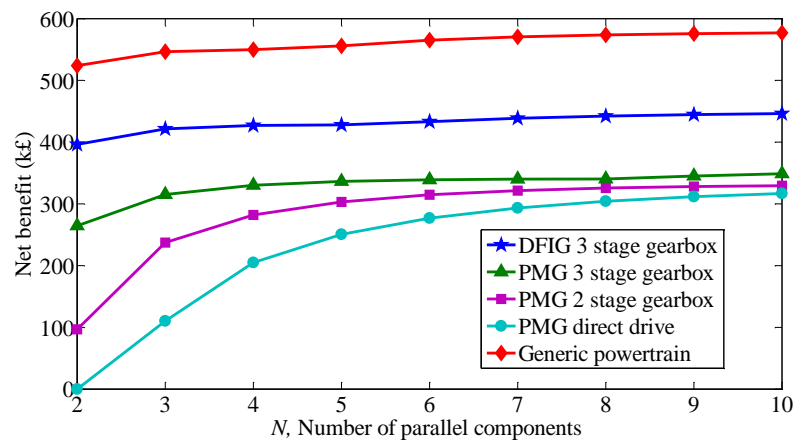

Fig. 5. Maximum net benefit comparison of different powertrain types and number of parallel components for a $3 \mathrm{MW}$ wind turbine

\section{Results for different parallel powertrain configurations}

The net benefit of three configurations are shown in Fig. 6 for (a) generator and power converter both in parallel, (b) 
parallel generator only and (c) parallel converter only. The powertrain with generators and converters both in parallel offers the highest net benefit of over $£ 550 \mathrm{k}$. When the parallel powertrain includes only the generator, then there is still significant net benefit; when only the power converter is in parallel the net benefit is very modest.

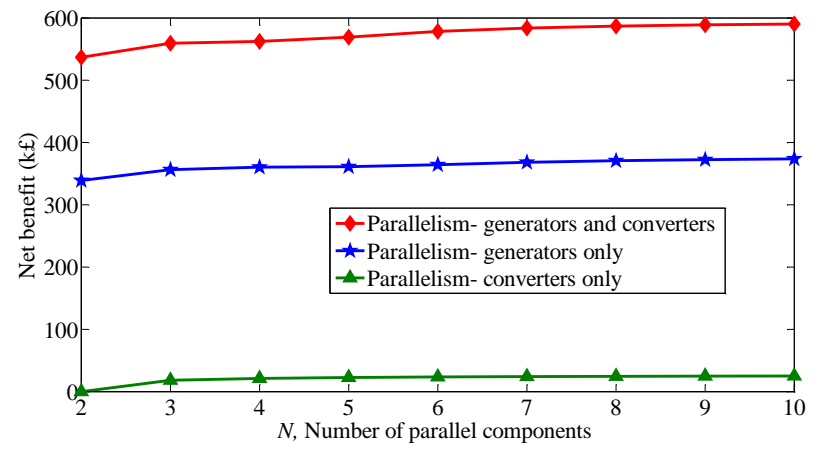

Fig. 6. Comparison of parallel powertrain configurations: parallelism in generator and power converter (Fig. 1b); parallelism in generator only (Fig. 1c); parallelism in power converter only (Fig. 1d) D. Sensitivity to different failure and repair rates from
different turbine types and sizes

By way of a sensitivity analysis, Fig. 7 shows the maximum net benefit with different failure and repair rates from Table I. The maximum net benefit of having a parallel powertrain is biggest for turbines with high powertrain failure rate and low repair rate; generally those that are larger turbines. For components with low failure rate and high repair rate, there is very low maximum net benefit and in some cases $N>1$ can lead to a net cost.

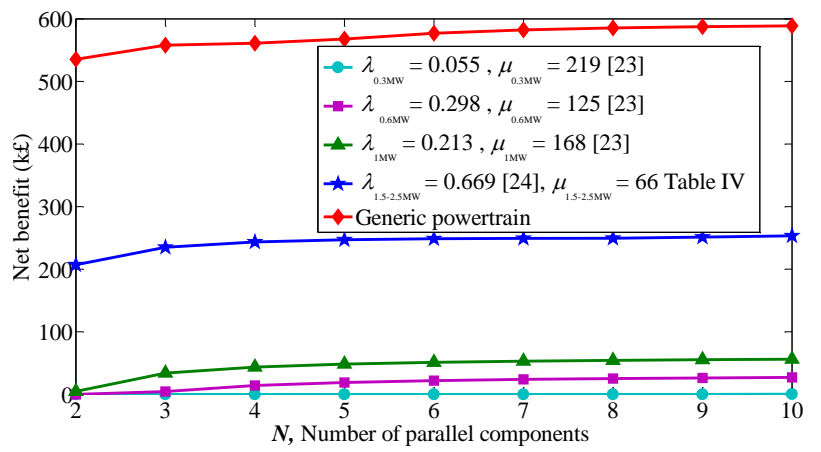

Fig. 7. Comparison of maximum net benefit based on different powertrain failure and repair rates drawn from different wind turbine populations

\section{E. Sensitivity to different sites and wind speed distribution}

Fig. 8 shows the sensitivity of the maximum net benefit using the generic powertrain failure and repair data $\left(m_{\lambda}=\right.$ 0.357, $m_{M T T R}=0.0073$ ) to different sites and their wind resource data in Table III. Higher mean wind speeds lead to a higher maximum net benefit, as marginal uptime produces more revenue and because the rest of the turbine has a higher failure rate.

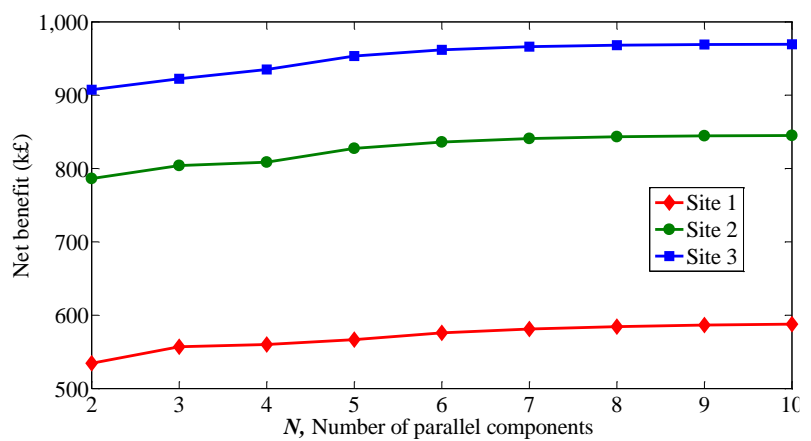

Fig. 8. Sensitivity analysis of maximum net benefit to sites using generic powertrain failure and repair rates

\section{DISCUSSION}

The following section is divided into discussions about the implications of the models developed in Section II, their application in Section III and the models' assumptions, their limitations and how these limitations might be addressed.

\section{A. Implications of the equivalent availability model}

\section{1) Parallel powertrains do not necessarily lead to}

higher equivalent availability

The first step in this paper considered a simple Markov model with one generator and one power converter being used to determine the baseline equivalent availability. It had been assumed that the addition of extra parallel powertrains (i.e. $N>$ 1 , where each subsystem is rated at $P / N$ ) would lead to an increase in equivalent availability. In actual fact the equivalent availability was found to be independent of $N$. Even when the simple model was updated to include more realistic repair paths, the equivalent availability was still independent of $N$.

\section{2) Effect of change in failure rate and repair rate on}

\section{simple availability model}

Equivalent availability can, however, be increased by: (a) reducing subsystem failure rates, (b) increasing subsystem repair rates and (c) increasing the power rating of each subsystem above $P / N$ implying an additional capital cost.

It has been suggested that a parallel powertrain might reduce repair time of each subsystem, therefore increasing repair rate and hence availability. There is some evidence that failure rate and repair rate vary with power rating; essentially a smaller subsystem fails less often and is quicker to repair. This was built into the simple model by incorporating a repair rate with power rating characteristic and a failure rate with power rating characteristic for the subsystems. The minimum power rating of a subsystem is $P / N$, so as $N$ increases the failure rate and repair rate both improve. This implies that if the size of the subsystem is scaled down, one will see an improved availability compared to larger subsystems.

These secondary effects of using $N$ parallel subsystems could be quite significant. For example, by varying only the failure and repair rates - based on industrial data - the equivalent availability improved by approximately $1.1 \%$ points when moving from $N=1$ (baseline) to $N=2$. Further increases can be observed as the number of parallel subsystems increase, 
but the marginal effect becomes smaller at larger $N$. It should be noted that these improvements will depend on the gradients of the repair rate and failure rate with power rating characteristics.

In offshore wind turbines, having smaller components could ease some aspects of operation and maintenance strategies for the powertrain subsystems. A response to a major failure of an offshore wind turbine electrical generator often requires the hiring of a heavy lift vessel which can lead to long mean times to repair. The operator may have to wait for the vessel to be available for hire and such vessels have limited accessibility to the site which is determined by weather conditions. The same failure type in one of $N$ parallel powertrain subsystems might be addressed using smaller, more ubiquitous vessels with less weather sensitivity. If that is the case then the failure will be repaired more swiftly. It is also possible that as the power rating of the powertrain subsystem reduces (i.e. $P / N$ gets smaller as $N$ increases) then on-board hoisting and lifting equipment within the nacelle can be used, further increasing the repair rate.

\section{3) Waiting to repair strategy}

It is often suggested that when parallel powertrain subsystems are used and there is a failure in one of the subsystems then one can afford to wait longer (than in the baseline $N=1$ case) to repair it without incurring the same downtime penalty. Assuming constant failure rates and that each subsystem is rated at $P / N$ then waiting longer implies a lower repair rate and hence a reduced availability. If there is potential to wait longer (e.g. to reduce hiring costs of vessels) it is only because of the failure and repair with power rating characteristics or that the power rating of each subsystem is greater than $P / N$.

A further point is worth mentioning. Throughout our model, for a given $N$, the repair rate between states was assumed constant. For example in Fig. 3(c) $\mu_{2 \rightarrow 1}=\mu_{3 \rightarrow 1}$. In reality one may be able to increase availability by adopting a variable strategy where $\mu_{3 \rightarrow 1}>\mu_{2 \rightarrow 1}$.

\section{B. Application of the equivalent availability models}

1) Results for a generic powertrain

The initial model implicitly assumed that the power rating of each subsystem was $P / N$. More explicitly, this was defined as $\alpha=1 / N$. It was shown that this $\alpha$ can be used as design variable with $1 / N \leq \alpha \leq 1$. A larger $N$ allows a wider choice of $\alpha$, and this can be beneficial in terms of balancing the upside of additional equivalent availability and the downside of additional capital costs. From the range of $\alpha$, the results show that the initial gradient is steep but the gradients change at points $\alpha=1 / 2,1 / 3,1 / 4,1 / 5 \ldots$ As $\alpha$ increases the gradients become shallower until a maximum availability is achieved at $\alpha=1$.

Fig. 4 shows that for $N=4$, moving from each subsystem being rated at $P / 4$ (i.e. $\alpha=1 / N$ ) to being rated at $P / 3$ (i.e. $\alpha=$ $1 /(N-1))$ gives an additional equivalent availability of $2.1 \%$. The subsystem aggregate power rating in this case would be $4 P / 3$, which implies - if one assumes that capital cost are proportional to the power rating - that the subsystem cost will be one third more expensive than the baseline powertrain cost.

This balance of additional availability and additional capital cost was evaluated for a particular wind turbine using a net benefit measure. In order to express the two measures in the same units, it was necessary to compute the revenue that is derived by the additional availability.

The results vary depending on the assumed turbine, its capacity factor, the availability of the rest of turbine, the turbine life and the site wind conditions as well as the revenue produced for unit energy produced. For the assumed values it can be seen that this net benefit generally increases as $N$ increases. This is because at higher $N$, there is a greater possible range of $\alpha$, and the same increase in availability can be produced by smaller additions to the aggregate power rating of the powertrain. The choice of $\alpha$ varies with $N$ and the type of turbine. Generally $\alpha_{\text {optimal }}>1 / N$. In some cases the net benefit can be zero or even negative, meaning that the parallel powertrain is disadvantageous and the additional costs outweigh the benefits.

\section{2) Results for different powertrain topologies}

In terms of different powertrain types, the highest net benefits are from those systems with lowest baseline availability and the lowest baseline capital costs, hence the Doubly Fed Induction Generator systems have the highest net benefit, whereas the direct drive permanent magnet generator systems enjoy lower net benefits when $N>1$.

\section{3) Results for different parallel powertrain \\ configurations}

Interestingly, in terms of net benefit, combining a parallel generator and a parallel power converter comes first, followed by the powertrain with the generator only in parallel, followed by the powertrain with the power converter only in parallel and then finally the baseline, series only powertrain.

This might be partly down to the failure rate, repair rate and cost data assumed for the generic powertrain where the generator has significantly higher baseline downtime than for the power converter; yet the generator is a little bit over twice the power converter cost.

4) Sensitivity to different failure and repair rates from different turbine types and sizes

The results of the sensitivity analysis for different data sources shows that the best net benefit will come from turbines with high powertrain failure rates, low repair rates, and lower capital cost. In some cases the parallel powertrain is clearly beneficial yet in other cases the benefit is marginal or 0 .

\section{5) Sensitivity to different sites and wind speed distribution}

The results of the sensitivity analysis for different sites show that parallel powertrains are more beneficial as the wind resource improves and the downtime of the rest of the turbine increases. 


\section{Assumptions and limitations of the equivalent availability} models

1) Limitations from failure rate and repair rate data

One limitation is the use of disparate onshore and offshore generator and power converter failure rate and repair rate data from a number of published sources. As better data becomes available it should be used instead. Having said that, the models themselves are independent of the data quality.

\section{2) Limitation of the cost model}

In this study the cost per unit power has been assumed constant and so a single 3MW generator and power converter cost the same as 3 parallel 1MW generators and power converters. In reality the cost per unit power tends to drop as powertrain units increase in power rating and as $N \rightarrow 1$ as fixed costs decrease in importance. If one were to plot the cost of a powertrain unit, $C$, against its power rating, $P$, one can fit a function of the form

$$
C=c+m P
$$

where $c$ is a fixed cost and $m$ is the marginal cost. If $c$ and $m$ are known then the specific powertrain cost then can be found

$$
\frac{C}{P}=\frac{c}{P}+m
$$

Equation (33) can be used to model the change in cost of the powertrain units as the number of parallel units, $N$, and hence their power rating, $P$, varies.

\section{3) Variation of $O \& M$ cost with $N$}

As well as additional capital costs, the parallel powertrain could potentially add to the O\&M costs. The unscheduled O\&M costs can be thought of as being proportional to the number of repair visits, $V$, to the powertrain. This is given by

$$
V=N \lambda_{\text {subsy stem }}
$$

For the case when the failure rate is assumed to be independent of the subsystem's power rating, then we can see from Fig. 9 that the number of visits and therefore the cost of unscheduled O\&M rise in line with the number of parallel subsystems. When the failure rate is given by (26) it can be seen that the failure rate of the subsystem and the number of visits will then be 1

$$
V=m_{\lambda} P \alpha N
$$

When $\alpha=1 / N$ then the number of visits and therefore unscheduled powertrain O\&M costs are independent of the number of parallel subsystems.

\section{4) Low wind speed operation}

The models presented here only consider power as the rated power and ignore the rest of the power curve. In the cases where $\alpha>1 / N$ then the total aggregate powertrain capability is $P \alpha N$. If there is a fault, then this becomes $P \alpha(N-1)$. At lower wind speeds it is possible that $P \alpha(N-1) \geq P(v)$ in which case the parallel powertrain system can still meet the required turbine power output at wind speed $v, P(v)$. This would imply that there can be additional energy production from the turbines with parallel powertrains, however this is not quantified here.

\section{5) Neglecting load losses}

When a generator fails but still rotates the generator will still give losses to the system, even though there is no power production in the generator. In this analysis this effect has been neglected.

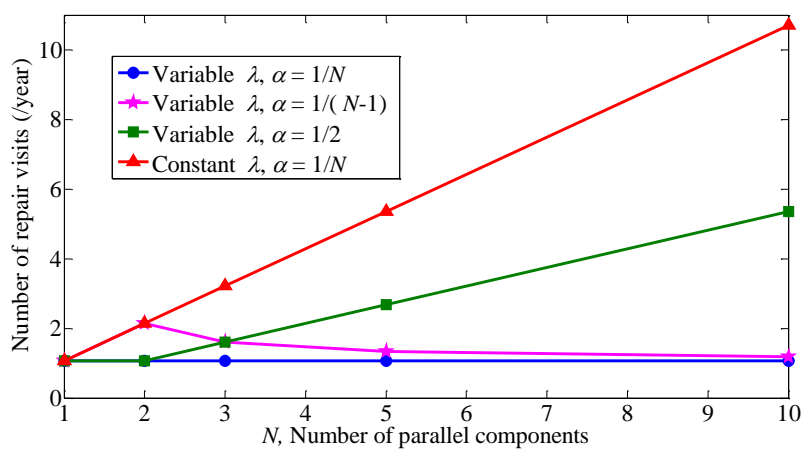

Fig. 9. Expected number of visits for repairs with increasing number of parallel subsystems

\section{SUMMARY AND CONCLUSIONS}

In this paper parallel powertrains for wind turbines have been analyzed and modeled to investigate the equivalent availability using a Markov state space model. A simple model of baseline system was modelled and the equivalent availability compared to $N$ parallel subsystems. A more advanced model of availability was investigated considering the more realistic repair transition paths, however it yielded the same results as the simple model. The simple model approach was extended to include failure and repair rate that varies with subsystem power rating. A factor $\alpha$ was introduced so that each subsystem can be rated at greater than $P / N$.

When the powertrain failure and repairs are assumed to be constant and they are rated at $P / N$ then there are no changes in availability with changes to $N$. If these rates vary with power rating then as $N$ increases, so does the availability. The highest availability is achieved when $\alpha=1$ but this is expensive.

Based on the limitations of this paper, future work should consider power capture of the parallel powertrain at below rated wind speeds. Better failure rate and repair rates of the powertrain at different power ratings would be welcome. A more sophisticated operation and maintenance strategy could be assessed.

Although the optimal parallel powertrain design will vary with turbine type and its location, a choice of $N>3$ appears to be beneficial. A good balance between additional availability and extra capital and O\&M costs can generally be struck when $\alpha=1 /(N-1)$. When using a parallel powertrain it is important that the technology used has lower failure rates and higher repair rates when $N$ increases and the subsystem power rating is reduced. 


\section{REFERENCES}

[1] R. Billinton and R. N. Allan, "Reliability Evaluation of Engineering Systems," Second edition, New York, Plenum Press, p. 12-15, 64-67, 221-302, 1983.

[2] J. W. Bennett, G. J. Atkinson, B. C. Mecrow and D. J. Atkinson, "FaultTolerant Design Considerations and Control Strategies for Aerospace Drives," IEEE Trans. Ind. Elect., vol. 59, no. 5, pp. 2049-58, May 2012.

[3] S. Schroder et al., "Modular High-Power Shunt-Interleaved Drive System: A Realization up to 35 MW for Oil and Gas Applications," IEEE Trans. Ind. Appl., vol. 46, no. 2, pp. 821-830, March-April 2010.

[4] J. Downer, "When failure is an option: Redundancy, reliability and regulation in complex technical systems." Centre for Analysis of Risk and Regulation, London School of Economics, 2009.

[5] H. Polinder, F. F. A. Van Der Pijl, G.-J. De Vilder, and P. J. Tavner, "Comparison of direct-drive and geared generator concepts for wind turbines," IEEE Trans. on Energy Convers., vol. 21, no. 3, pp. 725733, Sep. 2006.

[6] M. A. Mueller, H. Polinder, "Electrical Drives for Direct Drive Renewable Energy Systems," Woodhead Publishing Limited, Cambridge, UK, 2013, pp. 1-23,139-154.

[7] P. Tavner, S. Faulstich, B. Hahn, G. J. W. van Bussel, "Reliability \& availability of wind turbine electrical \& electronic components," $E P E$ Journal, no. 4, pp. 45-50, Sept. 2015.

[8] P. Tavner, "Reliability, Availability And Maintenance of Offshore Wind Turbines", First Edition, London, UK, IET, pp. 39-73, 2012.

[9] S. Faulstich, B. Hahn, and P. J. Tavner, "Wind turbine downtime and its importance for offshore deployment," Wind Energy, vol. 14, pp. 327337, April 2011

[10] G. Bywaters, V. John, J. Lynch, P. Mattila, G. Norton, and J. Stowell, "Northern Power Systems WindPACT drive train alternative design study report," NREL, Golden, Colorado, Report no. NREL/SR-50035524, October 2004

[11] J. Cotrell, "A preliminary evaluation of a multiple-generator drivetrain configuration for wind turbines," $21^{\text {st }}$ American Society of Mechanical Engineers (ASME) Wind Energy Symposium, Reno, Nevada, pp. 1-9, Jan. 2002.

[12] K. P. Astad and M. Molinas, "Double input AC/AC nine-switch converter for multiple-generator drivetrain configuration in wind turbines," IEEE Intern. Symposium on Ind. Electron.(ISIE), Bari, pp. 2382-2387, Jul. 2010.

[13] S. Faulstich, B. Hahn, H. Jung, and K. Rafik, "Suitable failure statistics as a key for improving availability," European Wind Energy Conference, Marseille, pp. 1-3, Jan. 2009.

[14] A. Mikhail, "Distributed generation drivetrain for high torque wind turbine applications," CEC-500-2011-002.

[15] C. Andrei, S. Serowy, F. Barenhorst, B. Riemer, R. Schelenz, and K. Hameyer, "Alternative wind turbine drive train with power split and high-speed generators," European Wind Energy Conference, Paris, France, Nov. 2015.

[16] J. Birk and B. Andresen, "Parallel-connected converters for optimizing efficiency, reliability and grid harmonics in a wind turbine," Power Electronics and Applications, 2007 European Conference on, Aalborg, 2007, pp. 1-7.

[17] V. Najmi, J. Wang, R. Burgos, and D. Boroyevich, "Reliability modeling of capacitor bank for modular multilevel converter based on markov state-space model," IEEE Applied Power Electronics Conference (APEC), Charlotte, NC, pp. 2703-2709, Mar. 2015.

[18] P. Albrecht, J. Appiarius, E. Cornell, D. Houghtaling, R. McCoy, E. Owen, and D. Sharma, "Assessment of the reliability of motors in utility applications-updated," IEEE Trans. Energy Convers., vol. EC-1, no. 1, pp. 39-46, (current version) Jan. 2009.

[19] P. O’Donnell, "IEEE reliability working group, report of large motor reliability survey of industrial and commercial installations. Part I and II," IEEE Trans. on Ind. Appl., vol. 1A-21, no. 4, pp. 853-872, July 1985.

[20] O. V. Thorsen and M. Dalva, "Survey of faults on induction motors in offshore oil industry, petrochemical industry, gas terminals, and oil refineries," IEEE Trans. Ind. Appl., Vancouver, BC, vol. 31, no. 5, pp. 1186-1196, Oct. 1995.

[21] J. Carroll, A. McDonald, and D. McMillan, "Failure rate, repair time and unscheduled O\&M cost analysis of offshore wind turbines," Journal on Wind Energy, vol. 17, pp. 657-669, Aug. 2015.
[22] F. Spinato, P. J. Tavner, G. J. W. van Bussel, and E. Koutoulakos, "Reliability of wind turbine subassemblies," IET Renew. Power Gener., vol. 3, no. 4, pp. 387-401, Dec. 2009.

[23] F. Spinato, "The reliability of wind turbines," PhD Thesis, School of Engineering, University of Durham, UK, 2008.

[24] J. Carroll, A. McDonald, and D. McMillan, "Reliability comparison of wind turbines with DFIG and PMG drive trains," IEEE Trans. Energy Convers., vol. 30, no. 2, pp. 663-670, May 2015.

[25] J. Carroll, A. McDonald, I. Dinwoodie, D. McMillan, M. Revie and I. Lazakis "A comparison of the availability and operation \& maintenance costs of offshore wind turbines with different drive train configurations." Accepted, Wiley Journal on Wind Energy. June 2016.

[26] International Electrotechnical Commission, "IEC 61400-1: Wind turbines Part 1: Design requirements." International Electrotechnical Commission, 2005

[27] J. Carroll, A. McDonald, D. McMillan, T. Stehly, C. Mone and B. Maples "Cost of energy for offshore wind turbines with different drive train types." EWEA 2015 conference, Paris, France, Nov. 2015.

\section{BIOGRAPHIES}

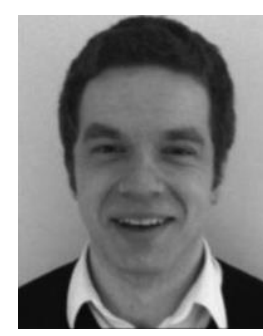

Alasdair McDonald received a M.Eng. degree in Electrical and Mechanical Engineering from the University of Durham, Durham, U.K., in 2004, and a Ph.D. degree from the University of Edinburgh, Edinburgh, UK., in 2008. He is a lecturer in the Electronic and Electrical Engineering Department, University of Strathclyde, Glasgow, U.K.

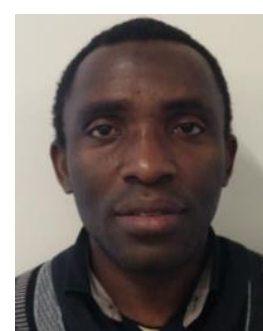

Godwin Jimmy received the B.Tech. degree in Electrical/Electronic Engineering from the Rivers State University of Science and Technology, Nigeria in 2003, and M.Eng. degree in Electrical Engineering from the University of Port Harcourt, Nigeria in 2009. He is currently working towards the Ph.D. degree at the University of Strathclyde, Glasgow, U.K. 